\title{
Improvement in the Prognosis of Cerebral Venous Sinus Thrombosis over a 22-Year Period
}

\author{
Dustin Anderson, Julie Kromm, Thomas Jeerakathil
}

\begin{abstract}
Background: Cerebral venous thrombosis is a rare cause of stroke, with a number of well-defined risk factors. However, there exist few studies that describe trends in the prognosis of this disease over time. Methods: A retrospective study was performed on patients diagnosed with cerebral venous thrombosis at the University of Alberta Hospital during two time periods: 1988-1998 (21 patients) and 1999-2009 (40 patients). Signs and symptoms, risk factors, imaging findings, etiologies, treatment modalities, and status at discharge were examined. Results: Headache, nausea and vomiting, focal motor deficit, and seizure were the most common signs and symptoms, and active hormonal contraception was the most commonly identified risk factor between the two cohorts. Hematoma and hyperdense sinuses were the most commonly identified CT findings between groups. Thrombophilia and the use of hormonal contraception were the most frequently identified etiologies between the two cohorts. Treatment was similar, with the majority of patients in both cohorts receiving unfractionated heparin as first-line therapy. Patients in the 1999-2009 cohort were significantly less likely to have a severe deficit or be dead at discharge (odds ratio $[O R]=0.178 ; 95 \%$ confidence interval $\left[C I_{95 \%}\right]=0.051,0.625$ ) and were more likely to have a favorable modified Rankin Scale score of 0 or 1 at discharge $\left(O R=7.98 ; C I_{95 \%}=1.79,35.71\right)$. Conclusions: Our data indicate a reduction in severe residual symptoms at discharge and improved functional status at discharge for patients presenting with cerebral venous thrombosis from 1999 to 2009, as compared with 1988-1998.
\end{abstract}

RÉSUMÉ: Amélioration des pronostics consécutifs à une thrombose des sinus veineux cérébraux au cours d'une période de vingt-deux ans. Contexte: Une thrombose des sinus veineux cérébraux, pour laquelle on sait qu'il existe un certain nombre de facteurs de risque précis, demeure une cause inhabituelle d'AVC. Cela dit, il n'existe que peu d'études ayant décrit l'évolution des pronostics se rattachant à cette complication. Méthodes: Nous avons mené une étude rétrospective portant sur des patients de l'Hôpital de l'Université de l'Alberta chez qui on avait diagnostiqué une thrombose des sinus veineux cérébraux. Notre étude s'est penché sur deux périodes : 1988-1998 (21 patients) et 1999-2009 (40 patients). Ont été examinés les signes cliniques et les symptômes, les facteurs de risque, les résultats d'examens IRM, les étiologies, les modalités de traitement et la situation des patients au moment d'obtenir leur congé de l'hôpital. Résultats: Des maux de tête, des nausées et des vomissements, de même qu'un déficit moteur affectant certaines régions du corps et des convulsions, se sont avérés les signes cliniques et les symptômes les plus répandus. Le fait de suivre de façon active un traitement hormonal de contraception s'est par ailleurs révélé le facteur de risque le plus souvent identifié dans les deux cohortes. De plus, des hématomes et l'hyperdensité des sinus ont été les deux anomalies les plus fréquemment observées, encore une fois dans les deux cohortes, à la suite d'examens tomographiques assistés par ordinateur. La thrombophilie et l'utilisation de contraception hormonale ont été les deux étiologies les plus fréquemment identifiées dans les deux cohortes. En ce qui concerne les modalités de traitement, elles se sont avérées similaires d'une cohorte à l'autre, la majorité des patients bénéficiant d'héparine non fractionnée comme traitement de première intention. Les patients de la cohorte 1999-2009 sont apparus nettement moins susceptibles d'être atteints d'un déficit sévère ou de décéder avant d'obtenir leur congé de l'hôpital (rapport de cotes $[R C]=0,178 ; I C_{95 \%}=0,051$; $0,625)$ et plus susceptibles d'obtenir un score favorable de 0 ou 1 à l'échelle modifiée de Rankin au moment de quitter l'hôpital $\left(R C=7,98 ; I C_{95 \%}=1,79 ; 35,71\right)$. Conclusions: Nos données indiquent ainsi une diminution des symptômes résiduels sévères des patients au moment où ils ont obtenu leur congé de l'hôpital. De plus, les patients de la cohorte 1999-2009 ayant été victimes d'une thrombose des sinus veineux cérébraux ont montré, au moment de quitter l'hôpital, une plus grande amélioration de leur état fonctionnel si on les compare aux patients de la cohorte 1988-1998.

Keywords: Cerebral venous sinus thrombosis, Stroke, Temporal trends, Prognosis

doi:10.1017/cjn.2017.236

Can J Neurol Sci. 2018; 45: 44-48

\section{INTRODUCTION}

Gowers ${ }^{1}$ was the first to describe cerebral venous thrombosis (CVT) in his seminal work on diseases of the nervous system. Since that time, and in concert with the evolution of novel noninvasive imaging techniques, ${ }^{2,3}$ our knowledge of CVT has greatly expanded. CVT accounts for $0.5 \%$ of all strokes, ${ }^{4}$ with an annual incidence of roughly 7 cases per million adults. ${ }^{5,6}$ Of all reported CVT cases, roughly $75 \%$ occur in females, ${ }^{6,7}$ likely related to such conditions as pregnancy, puerperium, and the use of oral contraceptives. ${ }^{5,8}$ Though a large number of additional CVT risk factors have been proposed, recent multicenter studies have helped clarify the most prevalent and critical

From the Department of Medicine (Neurology), University of Alberta, Edmonton, Alberta, Canada (DA, JK, TJ).

Received November 24, 2016. Final Revisions Submitted May 21, 2017. Date of Acceptance May 30, 2017.

Correspondence to: Thomas Jeerakathil, 7-112G Clinical Sciences Building, 11350 83rd Avenue, Edmonton, Alberta, Canada, T6G 2G3. Email: thomasj@ualberta.ca. 
risk factors. ${ }^{5-7,9-12}$ One of the largest studies to date, the International Study on Cerebral Vein and Dural Sinus Thrombosis (ISCVT), demonstrated that thrombophilia, puerperium, and infection are the most common risk factors in patients with CVT. ${ }^{7}$

The clinical presentation of CVT is highly variable, with the most common presentation being headache. ${ }^{7} \mathrm{~A}$ wide range of other symptoms-including focal motor deficits, focal sensory deficits, seizure, encephalopathy, and coma-have been well-described throughout the literature, though all of them lack specificity for CVT. ${ }^{6}$ While clinical presentation and known CVT risk factors can provide clues to the diagnosis of CVT, neuroimaging studies are key to establishing the diagnosis. A variety of imaging modalitiesincluding computed tomography (CT), magnetic resonance imaging (MRI), CT angiography (CTA) and venography (CTV), MR venography (MRV) and contrast enhanced MRV, and digital-subtraction angiography (DSA) - now exist to help confirm the diagnosis of CVT. Of these, MRI with contrast-enhanced MRV is the most sensitive modality for detection of CVT. ${ }^{4-13}$ Guidelines now exist for the treatment of $\mathrm{CVT},{ }^{14}$ with a focus on early administration of antithrombotic therapy, aggressive management of raised intracranial pressure, and prompt control of seizures.

Classically, the prognosis of CVT has been grim, what with a mortality rate as high as $50 \% .{ }^{15,16}$ However, with the evolution of modern neuroimaging techniques and interventions, in addition to the early administration of antithrombotic therapy, the prognosis of CVT is felt to have significantly improved. ${ }^{7,9,17-20}$ Surveillance studies describing the trends in the prognosis of CVT over time in defined populations are lacking. In the present study, we compare patients diagnosed with nonseptic CVT at the University of Alberta Hospital (UAH) from two time periods (1988-1998 and 1999-2009) in order to better understand the evolution and outcomes of this condition in a Canadian tertiary-care institution.

\section{MeTHODS}

A retrospective study was performed on patients diagnosed with CVT at the UAH during two sequential time periods: 19881998 and 1999-2009. The UAH is the only tertiary-care neurological and stroke center in a region with a catchment area of about 1.5 million persons. Patients were included in the study provided they had a diagnosis of nonseptic CVT (with ICD-9 codes 325 and 437.6 and ICD-10 codes I63.6, I67.6, and G08) and were over 18 years of age. From these patients, we included only those with nonseptic cerebral venous sinus thrombosis. All the patients in our study were admitted through the neurology service. The study received ethics approval from the Human Research Ethics Board of the University of Alberta.

Data extraction focused on presenting signs and symptoms; a comprehensive list of risk factors associated with $\mathrm{CVT} ;{ }^{7}$ imaging findings (including CT, CTA, CTV, MRI, MRA, MRV, and DSA); identified etiologies; treatment modalities; and clinical status at discharge. Discharge-modified Rankin Scale (mRS) score was determined from the allied health (rehabilitation) section on inpatient charts. Severe symptoms at discharge were defined as death, seizures, focal weakness, or language deficit. All data are presented as means \pm standard deviations or percentages. Univariate analysis was performed with chi-square tests, $t$-tests, or Wilcoxon's rank-sum tests where appropriate. Multivariate analysis was undertaken employing logistic regression. Statistical calculations were executed using OriginPro $8^{\circledR}$ (Origin Lab,
Northampton, MA) and SAS 9.3 (SAS Institute, Cary, NC). Results were considered significant when $p<0.05$.

\section{RESULTS}

Twenty-one patients from the 1988-1998 cohort (C1) and 40 patients from the 1999-2009 cohort (C2) were identified as having CVT. There were 19 females $(90.5 \%)$ and 2 males in $\mathrm{C} 1$, whereas there were 22 females $(55.0 \%)$ and 18 males in $\mathrm{C} 2$, and this difference was significant $(p=0.009)$. Age was comparable between the two groups, with the average age of $\mathrm{C} 1=35.2 \pm 15.9$ and $\mathrm{C} 2=40.7 \pm 15.4$ years $(p=0.195)$. There was no significant difference in median time to presentation $(\mathrm{C} 1=3$ days, interquartile range $[I Q R]=1,6 ; \mathrm{C} 2=7$ days, $I Q R=1,10.5 ; p=0.193$ ) between the groups. Presenting signs and symptoms were similar between the two cohorts, with the most common being headache, nausea/vomiting, focal motor deficit, and seizure (see Table 1). Seizure at presentation was significantly more common in $\mathrm{C} 1$, as compared to $\mathrm{C} 2$. The most common identified CVT risk factor in both groups was active hormonal contraception (Table 2). Previous DVT was the only risk factor that was different between the two groups, being more frequent in $\mathrm{C} 2$.

Imaging findings were similar between both groups (Table 3). All patients received CT scanning, and in both cohorts the most frequent CT findings were hematoma and hyperdense sinuses. Rare CT findings from $\mathrm{C} 1$ included one patient with

Table 1: Presenting symptoms/signs

\begin{tabular}{|c|c|c|c|}
\hline & $\begin{array}{c}1988-1999 \\
(N=21)\end{array}$ & $\begin{array}{c}1999-2009 \\
(N=40)\end{array}$ & \\
\hline Symptom/sign & $n(\%)$ & $n(\%)$ & $p$ value \\
\hline Headache & $18(85.7)$ & $30(75.0)$ & 0.5124 \\
\hline Nausea/vomiting & $7(33.3)$ & $18(45.0)$ & 0.4234 \\
\hline Papilledema & $3(14.3)$ & $7(17.5)$ & 1.0000 \\
\hline Proptosis & $1(4.8)$ & $0(0.0)$ & 0.3443 \\
\hline Focal sensory & $3(14.3)$ & $6(15.0)$ & 1.0000 \\
\hline Visual defect & $1(4.8)$ & $10(25.0)$ & 0.0789 \\
\hline Confusion & $2(9.5)$ & $5(12.5)$ & 1.0000 \\
\hline Agitation & $3(14.3)$ & $2(5.0)$ & 0.3286 \\
\hline Somnolence & $1(4.8)$ & $7(17.5)$ & 0.2434 \\
\hline Gait disturbance & $0(0.0)$ & $2(5.0)$ & 0.5484 \\
\hline Photo/phonophobia & $2(9.5)$ & $6(15.0)$ & 0.7028 \\
\hline Meningismus & $0(0.0)$ & $2(5.0)$ & 0.5410 \\
\hline Fever & $0(0.0)$ & $1(5.0)$ & 1.0000 \\
\hline Cranial nerve findings & $2(9.5)$ & $2(5.0)$ & 0.6024 \\
\hline \multicolumn{4}{|l|}{ Severe symptoms } \\
\hline Focal motor & $11(52.4)$ & $15(37.5)$ & 0.2891 \\
\hline Seizure & $11(52.4)$ & $10(25.0)$ & 0.0475 \\
\hline Stupor & $2(9.5)$ & $2(5.0)$ & 0.6024 \\
\hline Coma & $1(4.8)$ & $1(2.5)$ & 1.0000 \\
\hline Death & $0(0.0)$ & $0(0.0)$ & 1.0000 \\
\hline Aphasia & $4(19.1)$ & $4(10.0)$ & 0.4291 \\
\hline Any severe symptoms & $15(71.4)$ & $23(57.5)$ & 0.811 \\
\hline
\end{tabular}


Table 2: Identified risk factors

\begin{tabular}{l|c|c|c}
\hline Risk factor & $\begin{array}{c}\mathbf{1 9 8 8 - 1 9 9 8} \\
(\mathbf{N = 2 1 )}\end{array}$ & $\begin{array}{c}\mathbf{1 9 9 9 - 2 0 0 9} \\
(\mathbf{N = 4 0 )}\end{array}$ & \\
\hline Diarrhea & $\boldsymbol{n}(\boldsymbol{\%})$ & $\boldsymbol{n}(\boldsymbol{\%})$ & $\boldsymbol{p}$ value \\
\hline Dehydration & $1(4.8)$ & $3(7.5)$ & 1.0000 \\
\hline Previous DVT & $2(9.5)$ & $5(12.5)$ & 1.0000 \\
\hline Thrombophilia & $0(0.0)$ & $8(20.0)$ & 0.0421 \\
\hline Malignancy & - & $3(7.5)$ & $\mathrm{N} / \mathrm{A}$ \\
\hline Previous thrombotic events & $0(0.0)$ & $6(15.0)$ & 0.0848 \\
\hline Pregnant/peripartum & $2(0.0)$ & $6(15.0)$ & 0.0848 \\
\hline Active hormonal contraception & $7(33.3)$ & $10(25.0)$ & 0.5545 \\
\hline Active hormone replacement & $1(4.8)$ & $1(2.5)$ & 1.0000 \\
\hline Active chemotherapy & $0(0.0)$ & $3(7.5)$ & 0.5449 \\
\hline FMHx of thrombotic event & $1(4.8)$ & $6(15.0)$ & 0.4047 \\
\hline FMHx of thrombophilia & $2(9.5)$ & $3(7.5)$ & 1.0000 \\
\hline Active smoker & $5(23.8)$ & $5(12.5)$ & 0.2912 \\
\hline
\end{tabular}

DVT $=$ deep vein thrombosis; FMHx $=$ family history; $/ \mathrm{A}=$ not applicable.

intraventricular hemorrhage (IVH) and another with a dilated superior orbital vein, whereas temporal metastasis was noted in one patient from C2 (data not shown). There were $90.5 \%(18 / 21)$ of patients from the first cohort who received MRI and $87.5 \%$ $(35 / 40)$ in the second. On MRI, sinus thrombus was detected in roughly three-quarters of patients in each cohort. Intracranial hemorrhage (ICH) was also common among the two groups, with approximately $30 \%$ of patients in each group demonstrating this finding. Seven C1 patients (33.3\%) underwent DSA, all demonstrating the presence of a venous thrombus. A total of 5 patients $(12.5 \%)$ from the $\mathrm{C} 2$ cohort also had a cerebral angiogram. As with $\mathrm{C} 1$, all 5 had demonstrated thrombus on cerebral angiogram.

Table 3: CT and MRI findings

\begin{tabular}{l|c|c|c}
\hline CT & $\begin{array}{c}\mathbf{1 9 8 8 - 1 9 9 8} \\
(\boldsymbol{N}=\mathbf{2 1})\end{array}$ & $\begin{array}{c}\mathbf{1 9 9 9 - 2 0 0 9} \\
(\boldsymbol{N}=\mathbf{4 0})\end{array}$ & \\
\hline Finding & Frequency, $\boldsymbol{n}(\boldsymbol{\%})$ & Frequency, $\boldsymbol{n}(\boldsymbol{\%})$ & $\boldsymbol{p}$ value \\
\hline Hematoma & $7(33.3)$ & $13(32.5)$ & 1.0000 \\
\hline $\begin{array}{c}\text { Subarachnoid } \\
\text { hemorrhage }\end{array}$ & $2(9.5)$ & $6(15.0)$ & 0.7028 \\
\hline Hyperdense veins/sinuses & $9(42.9)$ & $24(60.0)$ & 0.2806 \\
\hline Venous infarct & $2(9.5)$ & $4(10.0)$ & 1.0000 \\
\hline Edema & $3(14.3)$ & $9(22.5)$ & 0.5180 \\
\hline MRI & $\mathbf{1 9 8 8 - 1 9 9 8}$ & $\mathbf{1 9 9 9 - 2 0 0 9}$ & \\
\hline Finding & $(\boldsymbol{N}=\mathbf{1 9})$ & $\mathbf{N 5})$ & \\
\hline Sinus/venous thrombus & $16(76.2)$ & $31(77.5)$ & 1.0000 \\
\hline Venous infarct & $4(19.1)$ & $14(35.0)$ & 0.2461 \\
\hline Intracerebral hemorrhage & $6(28.6)$ & $12(30.0)$ & 1.0000 \\
\hline Subarachnoid hemorrhage & $2(9.5)$ & $2(5.0)$ & 0.5987 \\
\hline & Frequency, $\boldsymbol{n}(\boldsymbol{\%})$ & Frequency, $\boldsymbol{n}(\boldsymbol{\%})$ & $\boldsymbol{p}$ value \\
\hline
\end{tabular}

Table 4: Etiologies

\begin{tabular}{l|c|c|c}
\hline & $\mathbf{1 9 8 8 - 1 9 9 8}$ & $\mathbf{1 9 9 9 - 2 0 0 9}$ & \\
\hline Etiology & $\boldsymbol{n}(\boldsymbol{\%})$ & $\boldsymbol{N}(\boldsymbol{\%})$ & $\boldsymbol{p}$ value \\
\hline Idiopathic & $4(19.1)$ & $17(42.5)$ & 0.0911 \\
\hline Dehydration & $1(4.8)$ & $4(10.0)$ & 0.6563 \\
\hline Thrombophilia $^{*}$ & $6(28.6)$ & $5(12.5)$ & 0.1643 \\
\hline Hormonal medication & $5(23.8)$ & $3(7.5)$ & 0.1104 \\
\hline Malignancy & $0(0.0)$ & $5(12.5)$ & 0.1543 \\
\hline Pregnancy/peripartum & $1(4.8)$ & $2(5.0)$ & 1.0000 \\
\hline Multiple etiologies & $4(19.1)$ & $4(10.0)$ & 0.4291 \\
\hline
\end{tabular}

*The identified thrombophilias in the 1988-1998 cohort were systemic lupus erythematosus (SLE, one patient); SLE with anti-phospholipid antibody syndrome (antiphospholipid antibody syndrome [APLA], one patient); paroxysmal nocturnal hemoglobinuria (one patient); APLA with protein S deficiency (one patient); factor V Leiden mutation (heterozygous, one patient); and polycythemia rubra vera (one patient). The thrombophilias identified in $\mathrm{C} 2$ were protein $\mathrm{S}$ deficiency (one patient), APLA (two patients), hyperhomocysteinemia (one patient), and factor V Leiden mutation (one patient).

There was no significant difference between the two groups with respect to CVT etiologies (Table 4). The most common etiologies in $\mathrm{C} 1$ were thrombophilia and the use of hormonal medications. In $\mathrm{C} 2$, thrombophilia (5 patients, 12.5\%) and malignancy (5 patients, $12.5 \%$ ) were common etiologies, though an etiology was not identified in 17 patients $(42.5 \%)$. The identified malignancies were breast cancer (3 patients), colon cancer (1 patient), and brain cancer (grade IV astrocytoma, 1 patient).

Anticoagulation with unfractionated heparin or lowmolecular-weight heparin was the most common treatment modality between the two cohorts, with 18 patients $(85.7 \%)$ from $\mathrm{C} 1$ and $36(90.0 \%)$ from $\mathrm{C} 2$ undergoing this treatment. We found that $71.4 \%$ of patients in $\mathrm{C} 1$ and $72.5 \%$ of $\mathrm{C} 2$ patients were also bridged to warfarin during hospitalization. Thrombolytics were rarely used in the treatment of CVT, with only 3 patients $(14.3 \%)$ in the $\mathrm{C} 1$ group and $2(5.0 \%)$ in the $\mathrm{C} 2$ group undergoing catheter-based intracranial thrombolysis. Similarly, antiplatelet agents were used in only $9.5 \%$ of $\mathrm{C} 1$ patients and $15 \%$ of $\mathrm{C} 2$ patients.

At discharge, 4 patients $(19.1 \%)$ from the $\mathrm{C} 1$ group and 2 patients $(5.0 \%)$ from the $\mathrm{C} 2$ cohort died during the course of hospitalization, but this difference was not statistically significant (Table 5). Ongoing seizure activity at the time of discharge was more common in the $\mathrm{C} 1$ cohort, as compared to the $\mathrm{C} 2$ cohort. These were continued intermittent seizures, as no patients had partial or generalized status epilepticus. Other individual deficits (including focal motor, focal sensory, and language deficits) were not significantly different between groups at discharge. Patients in the second cohort were significantly less likely to have at least one severe deficit or to have died at discharge, and this difference persisted after adjustment for age and sex (odds ratio $[O R]=$ 0.178 ; $95 \%$ confidence interval $\left.\left[C I_{95 \%}\right]=0.051,0.625\right)$. Similarly, patients in the second cohort were considerably more likely to have a favorable $\mathrm{mRS}$ score of 0 or 1 at discharge (Table 5). This difference persisted after adjustment for age and sex $\left(O R=7.98 ; C I_{95 \%}=1.79,35.71\right)$. The average length of stay was 


\section{Table 5: Clinical status at discharge}

\begin{tabular}{l|c|c|c}
\hline & $\mathbf{1 9 8 8 - 1 9 9 8}$ & $\mathbf{1 9 9 9 - 2 0 0 9}$ & \\
\hline Status & $\boldsymbol{n}(\boldsymbol{\%})$ & $\boldsymbol{N}(\boldsymbol{\%})$ & $\boldsymbol{p}$ value \\
\hline Death & $4(19.1)$ & $2(5.0)$ & 0.1688 \\
\hline Seizure & $10(47.6)$ & $5(12.5)$ & $\mathbf{0 . 0 0 4 4}$ \\
\hline Focal weakness & $9(42.9)$ & $10(25.0)$ & 0.2440 \\
\hline Language deficit & $1(4.8)$ & $3(7.5)$ & 1.0000 \\
\hline Vision deficit & $3(14.3)$ & $6(15.0)$ & 1.0000 \\
\hline Focal sensory & $3(14.3)$ & $2(5.0)$ & 0.3286 \\
\hline Gait disturbance & $1(4.8)$ & $2(5.0)$ & 1.0000 \\
\hline Any severe symptoms ${ }^{*}$ & $13(61.9)$ & $9(22.5)$ & $\mathbf{0 . 0 0 2 3} * *$ \\
\hline mRS score of 0 or 1 & $9(42.9)$ & $30(75)$ & $\mathbf{0 . 0 1 3 0 * *}$ \\
\hline
\end{tabular}

* Severe symptoms at discharge defined as any of death, continuing intermittent seizures, focal weakness, or language deficit.

${ }^{* *}$ This difference persisted after adjustment for age and sex (see Results section).

similar between groups, being $12.0 \pm 12.5$ days in $\mathrm{C} 1$ and $12.5 \pm 9.9$ days in $\mathrm{C} 2(p=0.449)$.

\section{DisCUSSION}

To our knowledge, our study represents the longest duration of surveillance for CVT hospitalizations within a defined catchment area to examine for trends in prognosis over time. Our study differs in purpose from such longitudinal studies as the Cerebral Vein Thrombosis International Study (CEVETIS), which took a single large cohort of patients and followed them over time to determine long-term outcomes. ${ }^{22}$ Similarly, the ISCVT clarified much in the way of our understanding of CVT, though it did not examine trends over time. ${ }^{7}$

Herein we retrospectively studied two cohorts $(C 1=1988$ 1998, C2 =1999-2009) of patients diagnosed with CVT at the $\mathrm{UAH}$, so that we might better understand the evolution of presentation and prognosis of this condition at a major Canadian tertiary-care institution. We found diverse etiologies, the most common being thrombophilia, hormonal medications, and malignancy. A number of cases, particularly in the $\mathrm{C} 2$ cohort, did not have an identified etiology.

The majority of patients diagnosed with CVT from our study were female. There was a strikingly higher preponderance of female patients in $\mathrm{C} 1$ compared to $\mathrm{C} 2$. In addition, the number of patients presenting in $\mathrm{C} 2$ was double that of $\mathrm{C} 1$. The population of Edmonton increased by $16 \%$ between the midpoints of the two study periods, which does not account for the discrepancy in numbers. This suggests that the condition may have been underdiagnosed at our institution during the first time period, and particularly among males. Both cohorts had similar rates of CT scan and MRI scan use. Improvements in diagnostic imaging modalities such as contrast-enhanced MRV and better availability of these modalities in the second cohort may have allowed for diagnosis of more patients of lower severity. It is possible that over the time period of the first cohort there were other patients not diagnosed and not included due to false-negative imaging, as a result of sequences that were less advanced than those in the second cohort. This may have produced some degree of ascertainment bias favoring better prognosis in the second cohort.
However, if the differences in outcome were entirely due to ascertainment bias, we would have expected a much greater baseline severity at presentation in the first cohort compared to the second. There did seem to be a trend toward a higher frequency of severe symptoms in the first cohort, who, overall, were $14 \%$ more likely to have at least one severe symptom at presentation. However, this difference was not statistically significant. Seizure occurrence was the only presentation variable that was significantly different between the two groups, with seizures being more common in $\mathrm{C} 1$. Despite being not significantly different at presentation, patients in $\mathrm{C} 1$ had a higher likelihood of being dead or having at least one severe deficit at discharge and were less likely to have a favorable discharge $\mathrm{mRS}$ score than those in $\mathrm{C} 2$. In contrast to the relatively small $14 \%$ discrepancy in severe symptoms at presentation, there was a nearly $40 \%$ difference in severe symptoms upon discharge in $\mathrm{C} 1$ compared to $\mathrm{C} 2$ (Table 5). This implies a greater deterioration over the length of admission of the $\mathrm{C} 1$ cohort versus that in the $\mathrm{C} 2$ cohort. The reasons for this are not known with certainty, as both cohorts received similar antithrombotic management. We are unable to compare the timing of initiation of anticoagulant therapy between cohorts, as that information was not collected. The $\mathrm{C} 1$ cohort patients actually presented an average of 4 days earlier from symptom onset than those in the $\mathrm{C} 2$ cohort. Even if we allow for a 1- to 2-day delay in obtaining imaging in $\mathrm{C} 1$ compared to $\mathrm{C} 2$ due to less timely access, it seems unlikely that anticoagulation would have been initiated longer after presentation in $\mathrm{C} 1$ compared to $\mathrm{C} 2$. It is likely that other advances in general stroke care at the UAH from 1999 to 2009 may have resulted in improved outcomes.

We found in-hospital mortality to be higher in the $\mathrm{C} 1$ group (19.1\%) compared to that in the $\mathrm{C} 2$ cohort $(5 \%)$, but this difference was not statistically significant and was based on only 6 deaths. Nonetheless, our combined mortality rate across both cohorts was $10 \%$. The $1988-1998$ cohort had a significantly lower proportion of patients with an $\mathrm{mRS}$ score of 0 to 1 . In contrast, $75 \%$ of the patients in the 1999-2009 cohort had an mRS score of 0 to 1 . We were not able to detect any differences in investigation, management, and etiology between our two cohorts that could clearly explain the discrepancies in outcome.

\section{Study Limitations AND STRENGThS}

There are several limitations to our study to be noted. This research was retrospective in nature and relied on ICD-9 and ICD-10 codes to identify only CVT patients who were admitted to hospital. We may have missed patients with less severe disease seen in neurological clinics. Where inpatients are concerned, studies suggest that ICD codes have reasonable sensitivity and specificity to detect CVT. ${ }^{21}$ It is therefore unlikely that we missed CVT patients in our target population of those patients severe enough to be admitted to hospital. The small study size is a limitation, and our sample may not provide adequate power to demonstrate statistically significant differences between the two groups. This is a limitation common to studies examining lowincidence conditions. We still consider it worthwhile to obtain regional data on such uncommon conditions as CVT. We discussed above the possibility that patients with milder symptoms in the first cohort may have been missed, and males in particular. Nonetheless, our conclusions still apply to those patients receiving a confirmed diagnosis of cerebral venous sinus 
thrombosis at a tertiary-care institution during the time periods in question. Finally, we do not have predmission $\mathrm{mRS}$ score available to ensure that differences between $\mathrm{mRS}$ score on discharge were not due to preexisting differences. Having said that, the patients in both cohorts were admitted from the community, were quite young on average, and had a similar proportion of severe neurological deficits at presentation, so we think it very likely that they were similar functionally upon preadmission.

Taken together, our data suggest improvements in the number of patients diagnosed, a reduction in severe residual symptoms at discharge, and improved functional status at discharge for patients presenting with CVT from 1999 to 2009 compared to patients from the time period of 1988-1998.

\section{ACKNOWLEDGMENTS}

The authors acknowledge the medical records department at Alberta Health Services for their assistance in gaining access to patient charts.

\section{Statement of Authorship}

TJ designed the study. JK and TJ performed the chart review. DA and TJ performed data analysis and wrote the manuscript.

\section{Disclosures}

Drs. Anderson and Kromm contributed equally to this work. They both hereby declare that they have nothing to disclose.

Dr. Jeerakathil reports grants from AIHS, grants from HSFC, grants from the Canadian Stroke Network, grants from the CIHR, grants from The University Hospital Foundation, and grants from Alberta Health Services, outside the submitted work. He also received honoraria from Bayer for two advisory board meetings within the last five years on a topic unrelated to this manuscript.

\section{REFERENCES}

1. Gowers WR. Clinical Lectures on Diseases of the Nervous System. Philadelphia: P. Blakiston, Son \& Company; 1895.

2. Poon CS, Chang JK, Swarnkar A, Johnson MH, Wasenko J. Radiologic diagnosis of cerebral venous thrombosis: pictorial review. AJR Am J Roentgenol. 2007;189(6 Suppl):S64-75.

3. Renowden S. Cerebral venous sinus thrombosis. Eur Radiol. 2004; 14(2):215-26.

4. Bousser MG, Ferro JM. Cerebral venous thrombosis: an update. Lancet Neurol. 2007;6(2):162-70.
5. Agnelli G, Verso M. Epidemiology of cerebral vein and sinus thrombosis. Front Neurol Neurosci. 2008;23:16-22.

6. Stam J. Thrombosis of the cerebral veins and sinuses. N Engl J Med. 2005;352(17):1791-8.

7. Ferro JM, Canhao P, Stam J, Bousser MG, Barinagarrementeria F, ISCVT Investigators. Prognosis of cerebral vein and dural sinus thrombosis: results of the International Study on Cerebral Vein and Dural Sinus Thrombosis (ISCVT). Stroke. 2004;35(3): 664-70.

8. Dentali F, Crowther M, Ageno W. Thrombophilic abnormalities, oral contraceptives, and risk of cerebral vein thrombosis: a metaanalysis. Blood. 2006;107(7):2766-73.

9. Wasay M, Bakshi R, Bobustuc G, et al. Cerebral venous thrombosis: analysis of a multicenter cohort from the United States. J Stroke Cerebrovasc Dis. 2008;17(2):49-54.

10. de Bruijn SF, de Haan RJ, Stam J.. Clinical features and prognostic factors of cerebral venous sinus thrombosis in a prospective series of 59 patients. For The Cerebral Venous Sinus Thrombosis Study Group. J Neurol Neurosurg Psychiatry. 2001;70(1):105-8.

11. Canhao P, Ferro JM, Lindgren AG, et al. Causes and predictors of death in cerebral venous thrombosis. Stroke. 2005;36(8):1720-5.

12. Masuhr F, Mehraein S, Einhaupl K. Cerebral venous and sinus thrombosis. J Neurol. 2004;251(1):11-23.

13. Leach JL, Fortuna RB, Jones BV, Gaskill-Shipley MF. Imaging of cerebral venous thrombosis: current techniques, spectrum of findings, and diagnostic pitfalls. Radiographics. 2006; 26(1 Suppl):S19-41; discussion S42-3.

14. Einhaupl K, Bousser MG, de Bruijn SF, et al. EFNS guideline on the treatment of cerebral venous and sinus thrombosis. Eur J Neurol. 2006;13(6):553-9.

15. Barnett HJ, Hyland HH. Noninfective intracranial venous thrombosis. Brain. 1953;76(1):36-49.

16. Nagpal RD. Dural sinus and cerebral venous thrombosis. Neurosurg Rev. 1983;6(3):155-60.

17. Baumgartner RW, Studer A, Arnold M, Georgiadis D. Recanalisation of cerebral venous thrombosis. J Neurol Neurosurg Psychiatry. 2003;74(4):459-61.

18. Girot M, Ferro JM, Canhao P, et al. Predictors of outcome in patients with cerebral venous thrombosis and intracerebral hemorrhage. Stroke. 2007;38(2):337-42.

19. Stolz E, Rahimi A, Gerriets T, Kraus J, Kaps M. Cerebral venous thrombosis: an all or nothing disease? Prognostic factors and long-term outcome. Clin Neurol Neurosurg. 2005;107(2):99-107.

20. Stolz E, Trittmacher S, Rahimi A, et al. Influence of recanalization on outcome in dural sinus thrombosis: a prospective study. Stroke. 2004;35(2):544-7.

21. Liberman AL, Kamel H, Mullen MT, Messe SR. International Classification of Diseases, Ninth Revision (ICD-9): diagnosis codes can identify cerebral venous thrombosis in hospitalized adults. Neurohospitalist. 2016;6(4):147-50.

22. Dentali F, Poli D, Scoditti U, et al. Long-term outcomes of patients with cerebral vein thrombosis: a multicenter study. J Thromb Haemost. 2012;10(7):1297-302. 